\title{
Real-world incidence and prevalence of low back pain using routinely collected data
}

\author{
Francis Fatoye $^{1}\left[\right.$ (i) $\cdot$ Tadesse Gebrye $^{1} \cdot$ Isaac Odeyemi $^{1}$
}

Received: 4 February 2019 / Accepted: 2 March 2019 / Published online: 8 March 2019

(c) The Author(s) 2019

\begin{abstract}
Low back pain (LBP) is a common health problem among adults of working age population, and its prevalence or incidence increases with increasing in age. The purpose of this review was to examine the real-world prevalence or incidence of LBP. A systematic review of the literature was conducted in accordance to the PRISMA guideline. Allied and Complementary Medicine Database, Cumulative Index of Nursing and Allied Health Literature, MEDLINE, SportDiscuss and Scopus electronic databases were searched using specifically developed search strategies to identify studies using patients' electronic medical records published in English up to February 2019. The quality of the included studies was assessed using a tool that consists of ten items addressing a risk of bias. The search yielded 756 published studies, of which 13 were deemed relevant and were included in this review. The included studies reported incidence or prevalence data from Canada, United States of America (USA), Sweden, Belgium, Finland, Israel, and Netherlands. All the included studies were assessed to be methodologically sound (low risk of bias). The prevalence and incidence of LBP ranged from 1.4 to $20.0 \%$ and $0.024-7.0 \%$, respectively. Three studies reported that the Odds of LBP in male patient was higher than their female counterparts (odds ratio $>1$; range 1.11-17.29). Nine studies identified the risk factors of LBP to be age, sex, and race. The remaining four studies also listed high intensity of physical activity, high spinal load, lifting, bending, and twisting as the risk factors for LBP. The results of this study highlighted there is a substantial difference within studies that estimated the prevalence and incidence of LBP. This finding could inform healthcare policy makers to critically examine the data sources of prevalence and incidence studies; this in return might help for resource allocation to manage the condition.
\end{abstract}

PROSPERO registration number: CRD42017078598, https://www.crd.york.ac.uk/prospero/.

Keywords Low back pain $\cdot$ Prevalence $\cdot$ Incidence $\cdot$ Epidemiology $\cdot$ Real world $\cdot$ Retrospective

\section{Introduction}

Low back pain is one of the common health problems that $50-80 \%$ of adults experience at some point in their life [1, 2]. It is believed that adults of working age are the most vulnerable group of LBP, which is ranked as the highest cause of disability than any other condition globally [3, 4]. The overall burden of LBP arising from ergonomic exposures at work was estimated at 21.8 million [95\% Confidence Interval (CI) 14.5-30.5] disability adjusted life years (DALYs)

Francis Fatoye

f.fatoye@mmu.ac.uk

1 Department of Health Professions, Faculty of Health, Psychology and Social Care, Manchester Metropolitan University, Manchester M15 6GX, UK in 2010 [3]. Of this, 8.3 M DALYs were in females and the remaining 13.5 million were in males.

Despite several peer-reviewed published studies on the prevalence or incidence of LBP, there is little consensus regarding its epidemiology and its risk factors [5-8]. For example, Hoy et al. [8] reported a point prevalence estimate of LBP that ranged from 1.0 to $58.0 \%$. A review of 56 studies from Walker has also indicated that the point prevalence of LBP was between 12.0 and $33.0 \%$ [7]. Moreover, 1-year and lifetime prevalence of LBP that ranged between $0.8 \%$ and $82.5 \%$ and $11.0-84.0 \%$, respectively, was reported from studies carried out worldwide including low-income countries [7, 8]. The prevalence of LBP in high-income countries was estimated at $30.0 \%$, which is higher than low-income countries, $18.0 \%$ [7]. The 1-year incidence of people who have any episode and first ever episode of LBP ranged from 1.5 to $36.0 \%$, and $6.3-15.4 \%$, respectively [7]. Further, it has been suggested 
that the prevalence or incidence of LBP is increasing with age $[9,10]$. A nationwide study in Finland reported that the prevalence of LBP for 7-year-olds, 10-year-olds and 14- to 16-year-olds was $1.0 \%, 6.0 \%$, and $18.0 \%$, respectively [9].

With regard to the potential risk factors of LBP, many personal and environmental factors have been identified [6, 11, 12]. Personal factors such as metabolism, biochemistry, physical factors (a long back), and depressive tendencies were identified as a risk factors of LBP [6], whereas job satisfaction, working with heavy weights, lengthy period of standing, forward bending, and carrying school backpacks were identified as environmental risk factors of LBP [11]. A recent study on gender-age environmental associates of adolescent LBP have also found that girls were likely to report LBP than boys [13].

The previous published reviews of prevalence and incidence of LBP studies were focused on evaluating peerreviewed journals conducted via population-based longitudinal and cross-sectional designs. One of the limitations of the longitudinal and cross-sectional study designs is lack of generalisability to the real-world settings [14]. Some of the reasons for their lack of generalisability include inappropriate subject selection criteria, inadequate randomisation, and insufficient sample size. Studies conducted using real-world data or routinely collected data from a variety of sources such as electronic health records, claims and billing activities, claims and billing data, and disease registries are believed to solve the problem of generalisability [15]. To the best of our knowledge, there is no systematic review that has reported incidence and prevalence of LBP in the real-world. The purpose of this review was, therefore, to systematically evaluate incidence and prevalence of LBP in the real-world. Understanding the prevalence and incidence of LBP from studies conducted using patients' electronic medical records may help put appropriate public health intervention in place to alleviate the burden associated with the condition.

\section{Methods}

This systematic review has been conducted in accordance with the Preferred Reporting Items for Systematic Reviews and Meta-Analysis (PRISMA) guideline and the recommendations listed by Gasparyan and colleagues [16, 17]. The review was registered with PROSPERO - the International Prospective Register of Systematic Reviews CRD: 42017078598.

\section{Search strategy}

A search of literature published on Allied and Complementary Medicine Database (AMED), Cumulative Index of Nursing and Allied Health Literature (CINAHL),
MEDLINE, SportDiscuss, and Scopus electronic databases were performed up to February 2019. The search terms used were back pain, chronic low back pain, chronic musculoskeletal pain, rheumatic low back pain, low back pain, real world, musculoskeletal disorder, incidence, prevalence, and epidemiology. These search terms were combined using conjunctions such as 'AND' and 'OR'. Inclusion criteria were: retrospective observational database studies investigating the prevalence and incidence of low back pain in adult population, conducted in any geographical location and published on any date, studies carried out using largescale database, and studies published in English language. Exclusion criteria: abstract unavailable, studies not yet fully completed, systematic reviews, narrative literature reviews, conference papers, cross sectional studies, surveys, and studies not published in English. Two independent researchers FF and TG were involved in the search and screening of the articles. Full-text articles were obtained and studies were excluded if they did not meet the inclusion criteria. Any disagreement in the study selection was resolved through discussion with a third reviewer IO where it was important. Studies utilising data from retrospective patient electronic medical records were included.

\section{Risk of bias assessment}

The included studies were assessed for quality using a risk of bias tool recommended by Hoy et al. [5]. This tool evaluates studies for measurement bias, selection and analysis bias, and contains ten items. The overall assessment of risk of bias was rated as low, moderate, and high risk of bias. Those studies, which were rated as high risk of bias (below 75\%), were excluded from the review.

\section{Data extraction and analysis}

Data extraction was made from the included studies. The following information were extracted: country, year of publication, citation, database, population type, sample size, case definition, age, sex, prevalence, and incidence. A descriptive analysis of the extracted results was performed. No metaanalysis was undertaken due to the heterogeneity of methodologies used across the included studies.

\section{Results}

\section{Search results}

The electronic database search yielded 756 published studies. After the removal of duplicates, 397 records remained for screening. Irrelevant titles $(n=262)$ were excluded, leaving $(n=135)$ for further examination by abstracts. After 
reading the abstracts, 27 potential studies were found eligible and their full-texts were printed. Finally, only 13 articles were included for data synthesis (Fig. 1).

\section{Description of the studies}

Various sources of data were reported in the included studies including the National Dutch Register [18]; Regie de'1 Assurance Maladie du Quebec [19]; Skane Health Care Register [20]; Truven Health Market Scan Commercial Claims and Encounters [21]; National Hospital Discharge Register of Finland [22]; registration Network Groningen [23], US Defence Medical Epidemiology Database [24], the Intego Database [25], and the Emergency Department Information System [26] (Table 1). The included studies were conducted in Belgium [25], Canada [19, 26], Finland [22], the Netherlands [18, 22, 27], Sweden [20], USA [21, 24, 28, 29], and Israel [30]. The sample size used to estimate the prevalence and incidence of LBP in the included studies ranged from
3900 to 7.5 million. The types of population included in the studies were industry workers (aerospace, defence industry, technology space and telecommunication), military personnel, self-reported patients, and adults living in USA, Quebec, and Sweden. All included studies scored $\geq 80 \%$ of risk of bias (low risk) for quality.

\section{Prevalence}

Five studies reported the prevalence rates of LBP (Table 2). The mean prevalence of LBP reported from the studies ranged from 1.4 to $15.6 \%[18,20,21,24,26]$. The highest prevalence rates of LBP [19] were reported from workers in the aerospace and defence industry in the Unites States Benchmark Companies, whereas the lowest prevalence rates were reported from the residents of Quebec, Canada [19]. The substantial differences within the two studies may explain that working in industry could be one of the major risk factors of LBP [19, 21]. Two studies
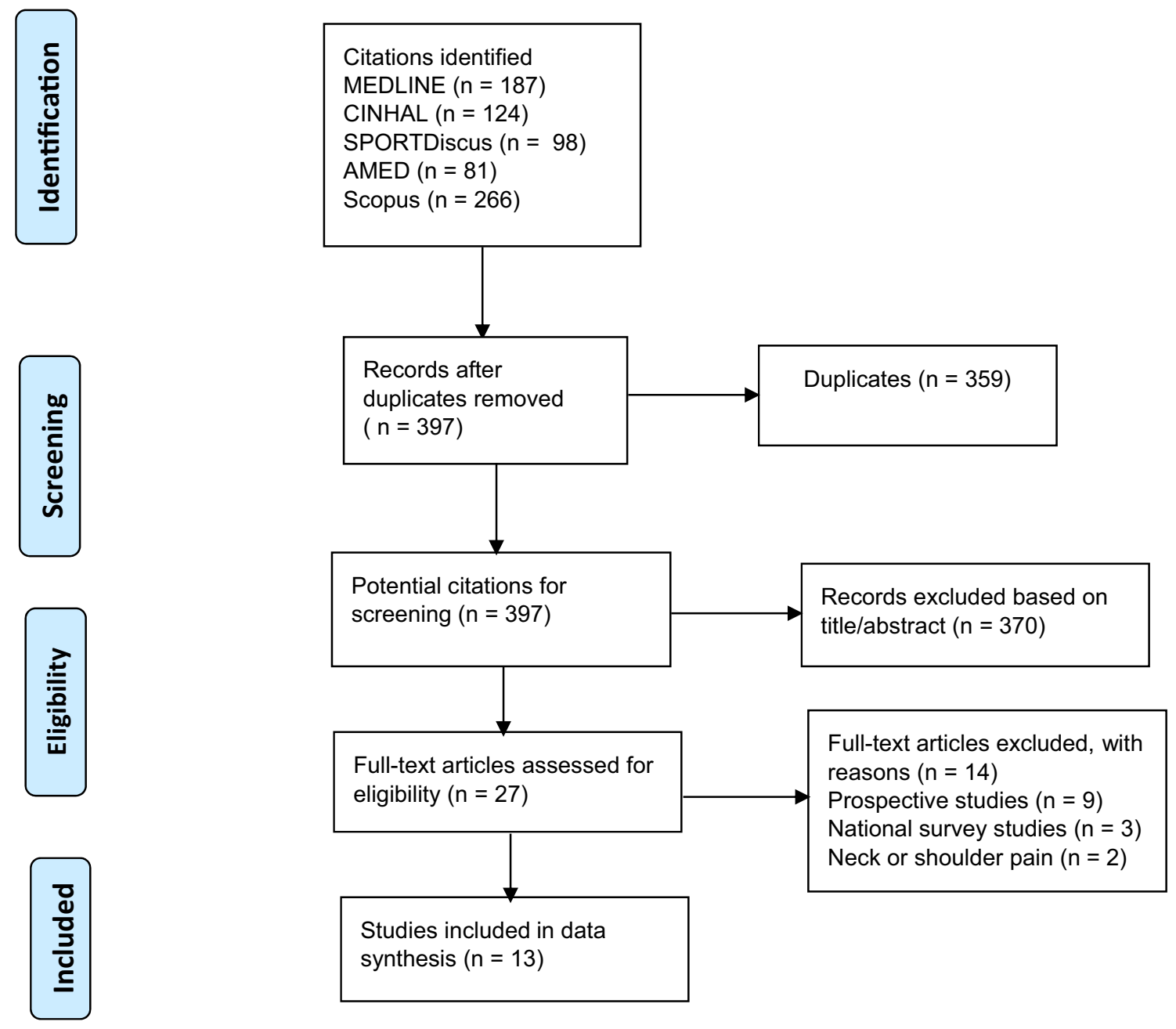

Fig. 1 Flow diagram demonstrating the study selection and inclusion process 
Table 1 Summary of the characteristics of the studies reporting prevalence/incidence of LBP

\begin{tabular}{|c|c|c|c|c|c|}
\hline References & Country (database) & Population type & Sample size & Age (years) & $\begin{array}{l}\text { Risk of } \\
\text { bias score } \\
(\%)\end{array}$ \\
\hline Beaudet et al. [19] & $\begin{array}{l}\text { Canada (Regie de'l Assur- } \\
\text { ance Maladie du Quebec) }\end{array}$ & All adults of Quebec & $\begin{array}{l}401,264 \\
M=49 \% ; F=51 \%\end{array}$ & $\geq 18$ & Low risk \\
\hline Goetzel et al. [21] & $\begin{array}{l}\text { USA (Truven Health Market } \\
\text { Scan Commercial Claims } \\
\text { and Encounters Database) }\end{array}$ & Industry workers & $\begin{array}{l}1.1-1.2 \text { million } \\
M=70 \%, F=30 \%\end{array}$ & 44.6 & Low risk \\
\hline Joud et al. [20] & $\begin{array}{l}\text { Sweden (Skane Health Care } \\
\text { Register) }\end{array}$ & $\begin{array}{l}\text { All inhabitants of Skane } \\
\text { population }\end{array}$ & $\begin{array}{l}938,397 \\
M=43 \%, F=57 \%\end{array}$ & $\geq 20$ & Low risk \\
\hline Mattila et al. [22] & $\begin{array}{l}\text { Finland (National Hospital } \\
\text { Discharge Register of } \\
\text { Finland) }\end{array}$ & Young male conscripts & 387,070 & $\geq 19$ & Low risk \\
\hline Spijker-Huiges et al. [23] & $\begin{array}{l}\text { Netherlands (Registration } \\
\text { Network Groningen) }\end{array}$ & $\begin{array}{l}\text { First episode of radiating } \\
\text { LBP }\end{array}$ & $\begin{array}{l}3900 \\
M=49 \%, F=51 \%\end{array}$ & $\geq 18$ & Low risk \\
\hline Ernat et al. [28] & $\begin{array}{l}\text { USA (US Defense Medical } \\
\text { Epidemiology Database) }\end{array}$ & Military personnel & 26,044 cases & $\geq 18$ & Low risk \\
\hline Knox et al. [24] & $\begin{array}{l}\text { USA (US Defence Medical } \\
\text { Epidemiology Database) }\end{array}$ & Military personnel & $\begin{array}{l}557,059 \text { cases }(13,754,261 \\
\text { person years })\end{array}$ & $\geq 18$ & \\
\hline Bartholomeeusen et al. [25] & Belgium (Intego Database) & Self-reported patients & $\begin{array}{l}74,863 \\
M=49.4 \%, F=50.6 \%\end{array}$ & $\geq 18$ & Low risk \\
\hline Kuijer et al. [18] & $\begin{array}{l}\text { Netherlands (National } \\
\text { Dutch Register) }\end{array}$ & Workers & $\begin{array}{l}7.5 \text { million } \\
M=48 \%, F=52 \%\end{array}$ & $\geq 18$ & Low risk \\
\hline Miedema et al. [27] & $\begin{array}{l}\text { Netherlands (Netherlands } \\
\text { Centre for Occupational } \\
\text { Diseases Registries) }\end{array}$ & Workers & 512,918 & $\geq 18$ & Low risk \\
\hline Waterman et al. [29] & $\begin{array}{l}\text { USA (Consumer Product } \\
\text { Safety Commission's } \\
\text { National Electronic Injury } \\
\text { Surveillance System) }\end{array}$ & All inhabitants & $\begin{array}{l}2,067,081 \text { cases }(1.48 \text { bil- } \\
\text { lion person year) }\end{array}$ & $\geq 24$ & Low risk \\
\hline Moshe et al. [30] & $\begin{array}{l}\text { Israel (Israel National } \\
\text { Defence) }\end{array}$ & Army recruits & 159,295 & $\geq 18$ & Low risk \\
\hline Edwards et al. [26] & $\begin{array}{c}\text { Canada (Emergency Depart- } \\
\text { ment Information System) }\end{array}$ & $\begin{array}{l}\text { All patients of Halifax, } \\
\text { Canada }\end{array}$ & 406,918 & $\geq 18$ & Low risk \\
\hline
\end{tabular}

\section{Incidence}

Table 2 Summary of the characteristics of the studies reporting prevalence of LBP

\begin{tabular}{ll}
\hline References & Prevalence \\
\hline Beaudet et al. [19] & $1.4 \%(M=1.6 \%, F=1.5 \%)$ \\
Goetzel et al. [21] & $15.6 \%(M=14.7 \%, F=17.8 \%)$ \\
Joud et al. [20] & $3.0 \%(M=1.0 \%, F=2.0 \%)$ \\
Spijker-Huiges et al. [23] & $1.7 \%$ \\
Edwards et al. 2018 [26] & $3.2 \%$ \\
\hline
\end{tabular}

$M$ male, $F$ female

have also reported that the prevalence rates of LBP in females were higher than males, which is contrary to the existing knowledge of LBP burden [20, 21].
The incidence rate of LBP was reported in ten studies $[18,21-25,27-30]$. The overall mean incidence of LBP reported from the nine studies ranged between 0.024 and $7.0 \%$. The highest and lowest incidence of LBP was reported in the USA and the Netherlands, respectively [21, 27]. One of the explanatory factor for the difference in the incidence rate estimate may be the type of population considered in the studies. For example, people working in the aerospace and defence industry in USA were highly vulnerable than those working in the healthcare, mining and quarrying sector in the Netherland. Two studies reported that the incidence of LBP in female was higher than in male $[21,25]$. Despite the difference in geographical locations where the studies were conducted, the incidence rates some studies have reported were approximately the same [22-24, 28] (Table 3). 


\section{LBP definition}

There was virtually no agreement among researchers regarding the definition of LBP (Table 4). Some of the definitions of LBP included are 3digits ICD-9 and ICD-10 codes, lumbar and other intervertebral disc disorder with radiculopathy, LBP (M54.5), and dorsalgia (M54.5). The study by Bartholomeeusen et al. [25] and Spijker-Huiges et al. [23] also reported LBP symptom/complaint (LO3), back syndrome without radiating pain (L84), and back syndrome with radiating pain (L86) for LBP definition. The Dutch Classification for Occupational Health Care and Social Affairs has also defined a nonspecific LBP as acute (L101, M545), subacute (L102, M545) and chronic (L103, M545).Overall, various kinds of LBP are used in the included studies. The use of various kinds of LBP definition may lead to the wrong of use of LBP treatment.

\section{Gender as a risk factor of LBP}

As it is shown in Table 5, six studies reported data that could be used to investigate the potential risk factor of LBP using odds ratios. The odds ratios were calculated by dividing the odds of male by the odds of female in the selected studies. If the odds ratio is greater than one, then being male is considered to be associated with having LBP since being male increases the odds of LBP. Of those six studies, three studies reported that being male was associated with having LBP higher than female $[18,19,23]$.

\section{Discussion}

The aim of this systematic literature review was to report LBP prevalence and incidence estimate from studies using patient electronic medical records. The included studies

Table 3 Summary of the characteristics of the studies reporting incidence of LBP

\begin{tabular}{ll}
\hline References & Incidence \\
\hline Goetzel et al. [21] & $7.0 \% M=6.7 \%, F=8.0 \%$ \\
Mattila et al. [22] & $2.0 \% M=1.3 \%, F=0.7 \%$ \\
Spijker-Huiges et al. [23] & $1.0 \%$ \\
Ernat et al. [28] & $3.0 \%$ \\
Knox et al. [24] & $4.0 \%$ \\
Bartholomeeusen et al. [25] & $5.1 \%(95 \%$ CI $4.9 \%, 5.3 \%), F=5.3 \%(95 \%$ CI 5.1\%, 5.5\%), M=4.9\% (95\% CI 4.7\%, 5.2\%) \\
Kuijer et al. [18] & $5.4 \% ; M=5.0 \%, F=4.0 \%$ \\
Miedema et al. [27] & $0.024 \%(95 \%$ CI $0.022-0.027 \%), M=0.031 \%(95 \%$ CI $0.028 \%, 0.035 \%), F=0.003(95 \%$ \\
& CI $0.002 \%, 0.005 \%)$ \\
Waterman et al. [29] & $0.14 \%$ \\
Moshe et al. 2016 [30] & $0.05 \%$ \\
\hline
\end{tabular}

$M$ male, $F$ female

Table 4 LBP definition of the studies

\begin{tabular}{ll}
\hline References & LBP definition \\
\hline $\begin{array}{l}\text { Beaudet et al. [19] } \\
\text { Joud et al. [20] }\end{array}$ & 3-digits ICD-9 codes 721, 722, 724 or 739 \\
Mattila et al. [22] & ICD-10: Lumbago with sciatica (M54.4), LBP (M54.5), other dorsaliga unspecified (M54.9) \\
& $\begin{array}{l}\text { ICD-10 (M51.1-lumbar and other intervertebral disc disorder with radiculopathy), M54.5-LBP and M54.9-dorsalgia. } \\
\text { ICD-9 by codes 7227C, 3539X, 7242A, 7245A, and 7249X }\end{array}$ \\
Spijker-Huiges et al. [23] & L02 and L03 for having pre-history and post-history of LBP in the DUTCH version of the ICPC-1 \\
Ernat et al. [28] & ICD-9CM code 724.20 \\
Knox et al. [24] & ICD-9CM code 724.20 \\
$\begin{array}{l}\text { Bartholomeeusenetal [25] } \\
\text { Kuijer et al. [18] }\end{array}$ & $\begin{array}{l}\text { LO3 (Low back symptom), L84 (back syndrome without radiating pain) or L86 (Back syndrome with radiating pain) } \\
\text { Moshe et al. 2016 [30] }\end{array}$ \\
$\begin{array}{l}\text { Criteria based on the Israeli Defence Force book of medical records } \\
\text { Edwards et al. 2018 [26] }\end{array}$ & $\begin{array}{l}\text { ICD codes: LBP with no potential nerve root involvement; LBP with potential nerve root involvement; and LBP } \\
\text { with attributed to trauma or other secondary factors }\end{array}$ \\
\hline
\end{tabular}

$I C D$ international classification of disease, ICPC international classification of primary care 
Table 5 The odds of gender (male and female) for LBP

\begin{tabular}{lc}
\hline References & Odds ratio \\
\hline Beaudet et al. [19] & 1.11 \\
Goetzel et al. [21] & 0.34 \\
Joud et al. [20] & 1.00 \\
Spijker-Huiges et al. [23] & 1.32 \\
Bartholomeeusen et al. [25] & 0.05 \\
Moshe et al. 2016 [30] & 1.47 \\
Kuijer et al. [18] & 17.29 \\
Edwards et al. 2018 [26] & 0.89 \\
\hline
\end{tabular}

reported incidence or prevalence data from North America and Europe including USA, the Netherlands, Canada, Sweden, Finland, Belgium and Israel. The methodological approach used as a search strategy identified no studies from developing countries. This may be due to the lack of proper and incomplete record keeping or registries in these countries.

It is well understood that the methodological quality of studies are different from one another. For this reason, the included studies were assessed for quality against the checklist criteria of Hoy et al. [31]. Overall, the included studies were assessed as low risk of bias $(\geq 80 \%)$. Assessment of the included studies for quality was important to have a reasonable trust on the findings of the review. It was also helpful to make comparison between studies. The sample size considered to estimate the prevalence or incidence of LBP in the included studies ranged from about 3900 to 7.5 million.

The findings of our review indicated that the mean prevalence and incidence of LBP ranged from 1.4 to $20.0 \%$ and 0.024-7.0\%, respectively. An annual prevalence of LBP ranged from 22.0 to $65.0 \%$ [7], and $8.0-82.0 \%$ [8] which is approximately four times higher than the current review was reported. Parallel to this, previous systematic review on the incidence LBP ranged from 24.0 to $80.0 \%$ [8]. Our results are lower than those of prospective studies on prevalence (6.0-25.0\%) and incidence (20.0-28.0\%) of LBP [32, 33]. One possible reasons for the discrepancy in the prevalence or incidence estimate within the reviewed studies could be the type of population and the methodology considered in each study.

Our findings of the prevalence and risk factors of LBP were also compared to those of reviews conducted in Africa $[2,34]$. The mean annual LBP prevalence among adults in Africa was 50.0\% [34]. We observed that the prevalence of LBP was approximately four times higher in Africa population compared to the prevalence of LBP reported in the current review. On the other hand, a contradiction were observed between Louw et al. [34] and Volinn [2] where the latter reported higher prevalence of LBP in high-income countries than low-middle income countries. Similarly, the main reason for the inconsistencies in the findings of LBP prevalence may be due to the study design, patient age, participants, and the mode of data collection adopted within the studies included in this review. The impact of reporting inconsistence prevalence or incidence of LBP within studies may have resulted in inefficient resource allocation. Thus, we suggest that using prevalence and incidence estimate from studies utilising real-world evidence is important for decision-making. With regard to risk factors of LBP, we observed a new insight within the current review. In the previous reviews, the risk factors of LBP were associated with psychological distress, depressive mood, and somatization [11], whereas in the present review it was suggested that sex might be a risk factor of LBP.

Similar to other systematic reviews, this review has some strengths and limitations. The strength of this review lies with the process of review it has conducted. Three independent reviewers were involved in the review process, whereas two of them have participated in the identification and analysis. The other strength of our review lies in the prevalence and incidence estimate reported; the samples' size of the included studies in the current review was based on a large sample, which enhances the generalisability of the findings. This review may have a selection bias due to the exclusion of studies with paediatric patients. Some of the included studies have also used information from a heterogeneous cohort and may not represent a routinely collected data. Further, it has been difficult to find literatures from developing countries; this was due to the lack of proper and incomplete record keeping or registries.

Based on the real-world evidence our findings suggest that LBP is a global burden to the individual, health system and society. In addition to other predictors or risk factors of LBP such as depression and psychological distress, being male or female may also be one that requires attention from clinicians and patients themselves. The results of this review could be used to inform healthcare authorities to evaluate alternative treatment options to prevent the incidence and reduce the prevalence of LBP. Further real-world studies are required to determine the effectiveness of such treatment options.

\section{Conclusion}

This systematic review highlighted there is a substantial difference within studies that estimated the prevalence and incidence of LBP. The prevalence and incidence estimate of LBP based on routinely collected data ranged from 1.4 to $20.0 \%$ and $0.024-7.0 \%$, respectively. The findings of this study have also indicated that sex might be a risk factor for LBP. We believe that our findings on real-world prevalence and incidence of LBP may help public health practitioners 
and healthcare policy makers to evaluate alternative treatment options to prevent the incidence and reduce the prevalence of LBP. Further research studies are required to estimate the prevalence and incidence and identify the risk factors for LBP, particularly in developing countries using patients of electronic medical records.

Author contributions FF and TG have contributed equally to this paper. FF and TG had conceived, designed, analysed the data, and interpreted the results of the work. FF, TG and IO wrote and critically revised the paper. All authors approved the final version of this manuscript.

Funding This research received no specific grant from any funding agency in the public, commercial, or not-for-profit sectors. The content of this study is solely the responsibility of the authors, and there is no financial support or benefits from commercial sources to declare.

\section{Compliance with ethical standards}

Conflict of interest The authors have no conflict of interests to declare.

Ethical approval The study is a systematic review. For this study ethical approval was not required. Note: Abstract for this study has already been published previously-https://www.valueinhealthjournal.com/ article/S1098-3015(18)31614-0/fulltext.

Open Access This article is distributed under the terms of the Creative Commons Attribution 4.0 International License (http://creativeco mmons.org/licenses/by/4.0/), which permits unrestricted use, distribution, and reproduction in any medium, provided you give appropriate credit to the original author(s) and the source, provide a link to the Creative Commons license, and indicate if changes were made.

\section{References}

1. Rubin DI (2007) Epidemiology and risk factors for spine pain. Neurol Clin 25(2):353-371

2. Volinn E (1997) The epidemiology of low back pain in the rest of the world: a review of surveys in low-and middle-income countries. Spine 22(15):1747-1754

3. Hoy D, March L, Brooks P, Woolf A, Blyth F, Vos T, Buchbinder R (2010) Measuring the global burden of low back pain. Best Pract Res Clin Rheumatol 24(2):155-165

4. Bressler HB, Keyes WJ, Rochon PA, Badley E (1999) The prevalence of low back pain in the elderly: a systematic review of the literature. Spine 24(17):1813

5. Hoy D, Brooks P, Woolf A, Blyth F, March L, Bain C, Buchbinder R (2012) Assessing risk of bias in prevalence studies: modification of an existing tool and evidence of interrater agreement. J Clin Epidemiol 65(9):934-939

6. Valat JP, Goupille P, Védere V (1997) Low back pain: risk factors for chronicity. Revue du rhumatisme (English ed.) 64(3):189-194

7. Walker BF (2000) The prevalence of low back pain: a systematic review of the literature from 1966 to 1998. Clin Spine Surg 13(3):205-217

8. Hoy D, Brooks P, Blyth F, Buchbinder R (2010) The epidemiology of low back pain. Best Pract Res Clin Rheumatol 24(6):769-781
9. Taimela S, Kujala UM, Salminen JJ, Viljanen T (1997) The prevalence of low back pain among children and adolescents: a nationwide, cohort-based questionnaire survey in Finland. Spine 22(10):1132-1136

10. Jeffries LJ, Milanese SF, Grimmer-Somers KA (2007) Epidemiology of adolescent spinal pain: a systematic overview of the research literature. Spine 32(23):2630-2637

11. Limon S, Valinsky LJ, Ben-Shalom Y (2004) Children at risk: risk factors for low back pain in the elementary school environment. Spine 29(6):697-702

12. Macfarlane GJ, Thomas E, Papageorgiou AC, Croft PR, Jayson MI, Silman AJ (1997) Employment and physical work activities as predictors of future low back pain. Spine 22(10):1143-1149

13. Grimmer K, Williams M (2000) Gender-age environmental associates of adolescent low back pain. Appl Ergon 31(4):343-360

14. Solem RC (2015) Limitation of a cross-sectional study. Am J Orthod Dentofac Orthop 148(2):205

15. Revicki DA, Frank L (1999) Pharmacoeconomic evaluation in the real world. Pharmacoeconomics 15(5):423-434

16. Moher D, Liberati A, Tetzlaff J, Altman DG, Prisma Group (2010) Preferred reporting items for systematic reviews and meta-analyses: the PRISMA statement. Ann Intern Med 151(4):264-269

17. Gasparyan AY, Ayvazyan L, Blackmore H, Kitas GD (2011) Writing a narrative biomedical review: considerations for authors, peer reviewers, and editors. Rheumatol Int 31(11):1409

18. Kuijer PPF, van der Molen HF, Schop A, Moeijes F, FringsDresen MH, Hulshof CT (2015) Annual incidence of non-specific low back pain as an occupational disease attributed to whole-body vibration according to the National Dutch Register 2005-2012. Ergonomics 58(7):1232-1238

19. Beaudet N, Courteau J, Sarret P, Vanasse A (2013) Prevalence of claims-based recurrent low back pain in a Canadian population: a secondary analysis of an administrative database. BMC Musculoskelet Disord 14(1):151

20. Jöud A, Petersson IF, Englund M (2012) Low back pain: epidemiology of consultations. Arthritis Care Res 64(7):1084-1088

21. Goetzel RZ, D'arco M, Thomas J, Wang D, Tabrizi MJ, Roemer EC, Yarborough CM (2015) Measuring the prevalence and incidence of low back pain disorders among American workers in the aerospace and defense industry. J Occup Environ Med 57(9):998-1003

22. Mattila VM, Sillanpää P, Visuri T, Pihlajamäki H (2009) Incidence and trends of low back pain hospitalisation during military service-an analysis of 387,070 Finnish young males. BMC Musculoskelet Disord 10(1):10

23. Spijker-Huiges A, Groenhof F, Winters JC, van Wijhe M, Groenier KH, van der Meer K (2015) Radiating low back pain in general practice: incidence, prevalence, diagnosis, and long-term clinical course of illness. Scand J Prim Health Care 33(1):27-32

24. Knox J, Orchowski J, Scher DL, Owens BD, Burks R, Belmont PJ (2011) The incidence of low back pain in active duty United States military service members. Spine 36(18):1492-1500

25. Bartholomeeusen S, Van Zundert J, Truyers C, Buntinx F, Paulus D (2012) Higher incidence of common diagnoses in patients with low back pain in primary care. Pain Pract 12(1):1-6

26. Edwards J, Hayden J, Asbridge M, Magee K (2018) The prevalence of low back pain in the emergency department: a descriptive study set in the Charles V. Keating Emergency and Trauma Centre, Halifax, Nova Scotia, Canada. BMC Musculoskelet Disord 19(1):306

27. Miedema HS, van der Molen HF, Kuijer PP, Koes BW, Burdorf A (2014) Incidence of low back pain related occupational diseases in the Netherlands. Eur J Pain 18(6):873-882

28. Ernat J, Knox J, Orchowski J, Owens B (2012) Incidence and risk factors for acute low back pain in active duty infantry. Mil Med 177(11):1348-1351 
29. Waterman BR, Belmont JP, Schoenfeld AJ (2012) Low back pain in the United States: incidence and risk factors for presentation in the emergency setting. Spine J 12(1):63-70

30. Moshe S, Zack O, Finestone AS, Mishal M, Segal N, Slodownik D, Yagev Y (2016) The incidence and worsening of newly diagnosed low back pain in a population of young male military recruits. BMC Musculoskelet Disord 17(1):279

31. Hoy D, Bain C, Williams G, March L, Brooks P, Blyth F, Buchbinder R (2012) A systematic review of the global prevalence of low back pain. Arthritis Rheum 64(6):2028-2037

32. Newlands C, Reid D, Parmar P (2015) The prevalence, incidence and severity of low back pain among international-level rowers. Br J Sports Med 49(14):951-956
33. Kanchanomai S, Janwantanakul P, Pensri P, Jiamjarasrangsi W (2015) A prospective study of incidence and risk factors for the onset and persistence of low back pain in Thai university students. Asia Pac J Public Health 27(2):NP106-NP115

34. Louw QA, Morris LD, Grimmer-Somers K (2007) The prevalence of low back pain in Africa: a systematic review. BMC Musculoskelet Disord 8(1):105

Publisher's Note Springer Nature remains neutral with regard to jurisdictional claims in published maps and institutional affiliations. 